\title{
Education and allocation of skills in Tunisia: evidence from an education reform
}

\author{
Tuomas Pekkarinen ${ }^{1}$ and Miquel Pellicer ${ }^{2 *}$
}

\author{
*Correspondence: \\ pellicer.miquel@gmail.com \\ ${ }^{2}$ German Institute of Global and \\ Area Studies (GIGA), Hamburg, \\ Germany \\ Full list of author information is \\ available at the end of the article
}

\begin{abstract}
An often cited explanation for the weak growth effects of education in developing countries is the misallocation of educated workers to inefficient activities in the public sector. This paper assesses the strength of this argument by studying the effect of educational attainment on employment status of Tunisian men. We exploit policy changes that restricted access to secondary education in the 1970's as an instrument for education and use data from 2004 Tunisian census as well as 2010 Labor Force Survey to estimate the effect of education on working in different sectors and within specific occupational categories. Consistently with the misallocation argument, we find that education increases employment, but that this increase is concentrated either in relatively low skill white collar occupations or in the public sector. Given that our instrument probably affected the academically weaker students this pattern of results suggests that the public sector might inefficiently reward titles.
\end{abstract}

Keywords: Returns to education; Middle East in North Africa; Public sector; Occupations

\section{Introduction}

Inefficient allocation of skilled labor across different economic activities is often cited as one the of the primary reasons for the disappointingly weak growth effects of public investments in education in many developing countries. According to this argument, often attributed to Pritchett (2001), education works as a gateway to inefficient activities, such as unproductive public sector employment, rather than boosting productivity in the competitive and open sectors of the economy.

Middle Eastern and North African (MENA) countries are usually portrayed as primary examples of countries where expectations related to educational investments have not been fulfilled. Even though these countries invested heavily in education after gaining independence in post WW II period, the economic growth has been disappointing. Indeed, Makdisi et al. (2003) show that the level education has not been a significant determinant of economic growth in MENA countries. The experience of Tunisia is a typical example of this pattern. Investment in education was for a long time larger than in most countries in the developing region. Despite these investments, however, both GDP growth and total factor productivity growth have been very low since the 1980's.

Previous literature on the effects of education investments in MENA countries has focused on the estimation of private returns to education and typically reports estimates

○2013 Pekkarinen and Pellicer; licensee Springer. This is an Open Access article distributed under the terms of the Creative Commons Attribution License (http://creativecommons.org/licenses/by/2.0), which permits unrestricted use, distribution, and reproduction in any medium, provided the original work is properly cited. 
that are comparable to the ones obtained in industrialized countries. This pattern of results would suggest that, at least at the private level, educational investment does pay off also in this region. However, previous literature also points to potential inefficiencies. Salehi-Isfahani et al. (2009) report estimates that seem to suggest that returns are convex in the level of education in Egypt and Iran and interpret this as evidence of "sheepskin effects", that is returns attached to official degrees rather than actual learning. Assaad (1997) and Tansel (2005) provide evidence on the attractiveness of public sector employment for university graduates in Egypt and Turkey, respectively.

However, due to lack of suitable instruments, this literature has been unable to address the causality of these estimates. Isolating the causal effect of education is important because the observed patterns could be driven by relevant unobserved factors correlated with educational attainment, such as the capacity to finance education or unobserved productive skills (credit constraints and ability bias, respectively). For instance, convexity of estimated returns to education could be due to the fact that higher levels of education are costly so that credit constrained individuals are left out, and extra return premia are generated for these levels. The attractiveness of the public sector to university graduates could be potentially driven by a successful public sector selection on the basis of ability. None of these explanations would imply that the education is used to access privately rewarding but inefficient activities.

This paper is an attempt to assess the extent of inefficient absorption of educated individuals by the public sector in Tunisia by providing evidence on the effect of education on the employment status of Tunisian men in different sectors. Our estimates purge the effect of education from the aforementioned biases by exploiting a policy change that restricted the access to secondary schools for several cohorts in the 1970's. We use this policy change as an instrument for educational attainment and use Tunisian census and labor force survey data to estimate the effect of educational attainment on occupational outcomes.

The education policy change we exploit took place after the rapid expansion of public education in the 1960's. This growth of public education led to increased budgetary pressures to which the Tunisian government responded by restricting the access to secondary education drastically. The promotion rates to secondary education were decreased by 15 percentage points starting in 1971 and remained at low levels until 1980 when they were increased again approximately back to the level where they were before 1971 . These policy changes, both limiting and subsequently loosening of entry to secondary school, generate between cohorts variation in educational attainment and we use this variation as an instrument for educational attainment. The first stage results suggest that the policy change is a strong instrument: individuals that were affected by the reform completed on average one grade less of education ${ }^{1}$. The compliers of our instrument (i.e. the people affected by the policy change) are likely to have been students at the margin of passing to secondary school and therefore probably academically weak in relative terms.

We use micro data from Tunisian 2004 census and 2010 Labor Force Survey to estimate the effect of educational attainment on employment and occupational status of men in different sectors, focusing on the distinctions between the public and the private corporate sector. Descriptive statistics and OLS results suggest no inefficient overrepresentation of educated workers in the public sector. The public administration does 
employ more college workers, but this appears to be due to the specific occupational structure of the sector, particularly its abundance of health and education workers. Hence, the descriptive evidence would suggest that educated workers are not allocated inefficiently in the Tunisian labor market and that we would need to look for alternative explanations for the lack of economic growth from educational investment.

However, using the changes in the access to secondary education as an instrument for education does deliver results that are consistent with inefficient absorption of educated workers by the public sector. First, IV estimates of the effect of education on working in the public sector exceeds the effect on working in the private sector. This suggests that educational attainment, when purged from the effect of other productive characteristics, works as a gateway to public sector jobs in the Tunisian labor market. The pattern, however, could still be driven by differing occupation structures across sectors. Our second set of results thus focuses on differences across sectors in selected occupations. We find no effect of education on white collar occupations in the multinational sector, with the exception of clerical work, the least skill-intensive of our white collar occupations. In contrast we find a clear effect of education on most white collar occupations in the public sector. The pattern is most striking for managerial occupations: this effect is large in the public sector, considerably weaker in the private Tunisian sector and essentially nonexistent in the multinational sector.

The interpretation of these results as inefficient absorption of educated workers by the public sector is strengthened by the fact that our estimates probably apply to relatively academically weak students that should have benefited least from the acquisition of technical skills at school. This is because the policy that we use as our instrument is likely to have shocked the education level of students at the margin of accessing secondary school. Consistent with this idea, we find no effect of education on natural science occupations in any sector even though natural science occupations should be the most skill intensive occupations in our data. We argue that the fact that education increased the chances of presumably "marginal" students to work as managers in the public sector but not in the multinational sector is consistent with the idea that the public administration hires and promotes workers inefficiently, rewarding titles rather than actual skills. Hence, even if our identification strategy does not allow us to formally distinguish the effects of titles from years of education, this pattern of results is consistent with the public sector sheepskins effects discussed in the earlier literature.

The rest of the paper is organized as follows. In the following section we present a short history of educational investment in Tunisia and describe the policy reform that we will exploit in our identification strategy. The third section describes the data sets used in the analysis and presents some descriptive statistics on the allocation of educated workers in the Tunisian labor market. We then move on to present the results on the effect of educational attainment on the employment status. We report IV estimates of the effect of education on the probability of working in different sectors on average as well as separately for certain occupations. The fifth section concludes.

\section{Education investment in Tunisia}

Tunisia obtained its independence from France in 1956 in a relatively peaceful way. A single-party regime ensued, led by the Neo-Destourian party that had fought and negotiated the independence. The political power was highly concentrated in the hands of the 
party leader, Habib Bourguiba. The party and its leader had a strong developmental and modernizing agenda. One of the key instruments of modernization was to be the spread of education to the Tunisian masses.

\subsection{Expansion of education after independence}

At the eve of independence the average level of educational attainment was very low in Tunisia. In 1955, primary school enrollment was only 30\% among 6-9 year olds and the overall illiteracy rate in the whole population was as high as $84 \%$ (Tarifa 1971). The new regime spent great efforts to expand education. An education reform in 1958 foresaw complete schooling of six year olds by 1967 and allowed for a relatively open access to secondary school (around 40\% access rate from primary to secondary) (Tibi 1974). Expenditures in education reached 4.3\% of GNP in 1965, larger than the average for any developing region (Bousnina 1991). Enrollment rates of 6-9 year olds soared to $70 \%$ in 1967 , only ten years after independence and enrollment in secondary schooling more than tripled from 1958 to 1966 (Tarifa 1971).

Despite the quantitative success of the policy of educational expansion, by the end of the 1960s several problems were identified. First, as enrollments increased, so did the budget required to sustain the system. By 1970, expenditures in education reached 6\% of GNP, a figure even higher than that of developed countries (UNESCO 1976 Yearbook, quoted in (Bousnina 1991)). As expansion at the primary level spilled over increasingly to the much more expensive secondary and tertiary levels, there was a risk of explosive budget increases. Second, repetition rates were high, both at the primary and secondary levels. The concern emerged that the expansion into the secondary level had been too massive, leading to unsustainable education budgets and large numbers of unprepared students in secondary schools who did not progress at the appropriate rate.

\subsection{The policy reform of the 1970's}

As a reaction to these problems the promotion rate into secondary school was dropped suddenly from $40 \%$ to around $25 \%$ in 1971 (see Figure 1). During a full decade promotion rates remained at such low levels. Meanwhile the budget, which in 1974 remained at 6.1 of GNP (UNESCO 1976 Yearbook, quoted in Bousnina (1991)), appears to have somewhat stabilized. However, these changes led to a new problem: a large amount of youth below 16 years old were left out of the educational system at an age where they were still not ready to join the workforce. In that context, promotion rates were brought back to around $40 \%$ in 1980 (Figure 1).

These two sudden changes in promotion rates form the basis for our instrument for education. There are several reasons why we believe these changes can be considered exogenous. First, the fact that promotion rates change so suddenly and remain relatively constant within each regime strongly suggests that it is driven by policy, not by some secular changes in cohorts. Second, contemporary observers appear to agree that the changes were policy induced, at least when it comes to the first drop (Tibi (1974), Allman (1979)). Finally, there is evidence that grades thresholds required to pass into secondary school were politically manipulated during that period. In the minutes of a 1974 meeting at the Education Ministry, it is stated that "We have admitted [to secondary school] only the candidates having passed the threshold except in the disadvantaged provinces, where, 


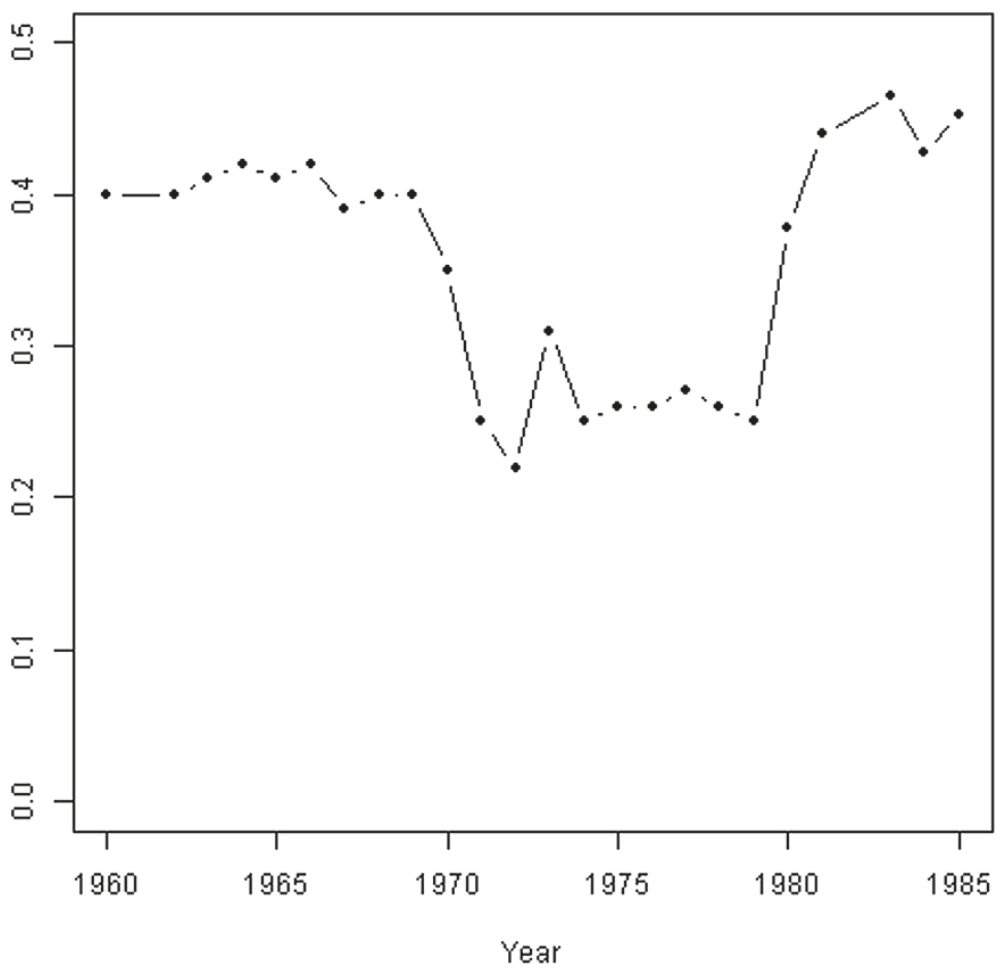

Figure 1 Promotion rates into secondary school. Share of students in the last year of primary school promoted to secondary school. Sources: (Tarifa 1971) and annual statistical reports on primary education by the Tunisian Ministry of Education.

as a political option, it was decided to lower the threshold to 9.6 [from the 'theoretical' threshold of 10]" (emphasis added), (Ministère de l'Education Nationale (1974)). This statement strongly suggests that promotion rates were seen as a relevant political issue that warranted government intervention and that the intervention was (partly) done by changing the passing threshold where and when necessary.

We construct an instrument for education using these changes in promotion rates. We call the years of low promotion rates, the low promotion regime. Our instrument is a variable that captures exposure of different cohorts to the low promotion regime. If no one repeated grades, the instrument would take value one for cohorts reaching 12 years old between 1971 and 1980. Because of grade repetition, cohorts older than that had some exposure to the low promotion regime whereas the younger of these cohorts had only a limited exposure. Below, we describe the instrument in more detail and show that the policy used had a strong impact on the number of grades completed as well as on the probability of continuing studies beyond primary school.

Under the LATE interpretation, the IV estimates that follow reflect the effect of schooling for the "compliers" of our instrument, i.e. the people whose schooling was affected by the policy. Although compliers are unobserved and we lack predetermined variables to characterize them, we conjecture that the compliers in our case ought to have been relatively academically weak students. This conjecture is based on the nature of the instrument, which made access to secondary school more difficult, thus presumably blocking 
schooling to the "marginal" students. The conjectured identity of the compliers plays a role in the interpretation of our results below.

\section{Data}

We use two datasets in our analysis: The 2004 Tunisian Census and the 2010 Tunisian Labor Force Survey (LFS) ${ }^{2}$. Our version of the 2004 Census has individual information on one fourth of Tunisian households (2,157,325 individuals). The LFS sample consists of 549,015 individuals. The census data are our primary source for the analysis; the LFS is used as a complement where appropriate.

\subsection{Variables}

Both datasets include individual information on education, labor market outcomes and demographic characteristics, as well as characteristics of the household such as possession of certain assets (cars, washing machines, etc.) which we will use to construct a wealth index ${ }^{3}$. In addition, both datasets provide sampling weights which we use in all our analyses below.

As was explained above, our analysis relies on policy changes affecting cohorts born around the 1960s. Thus, we restrict our sample to individuals born after 1945 and before 1980. This leaves us with around 10 to 15 cohorts before and after the cohorts affected by the policy and has the virtue of excluding most of retired people as well as students. Moreover, we observe a clear agglomeration of observations with round years of birth, i.e. at years ending in 0 or in 5 . This is likely to represent individuals unsure of their exact birth year. Because these individuals are not randomly selected, but rather appear to display particularly low education levels, we erase these observations. Finally, because the policy of interest had a substantially stronger impact on males than on females, we restrict our analysis to males. We end up with 354,610 census observations and 78,786 LFS observations ${ }^{4}$.

The main variables we will use in our analysis are the number of grades completed that we use to measure educational attainment, the occupation related variables (sector or place of employment and occupation) and the index of wealth. For education, both datasets already include variables on the level of education reached (none, primary, secondary, university) as well as a variable with the number of grades completed of the respective education level (for example, the data would tell that an individual reached secondary school, but completed only 2 grades of secondary school). From these two variables, we construct the total years of education ("grades completed") on the basis of official length of each level for these cohorts, assuming a primary education of 6 grades and a secondary education of 7 grades (the individual of the example would thus be assigned 8 grades completed).

The occupation-related variables include a variable on "workplace" and a 2-digit occupation category variable. The workplace variable includes as categories public administration, public companies, private Tunisian companies, multinational or mixed companies, shops, home, ambulant, agricultural, construction building, other construction sites and other places. From this variable, we will focus on the four first categories, public administration and the three types of company, which we will denote from now on "sectors". The occupation variable consists of 9 main categories, each subdivided into two to five subcategories. The main categories are management, scientists, technicians, clerks, vendors, 
farmers, craftsmen, machine operators and unskilled workers. We will mainly focus on the while collar workers which are the first four ones.

\subsection{Descriptive statistics}

We are primarily interested in the links between educational attainment, wealth, sector of employment and occupation. Table 1 presents the descriptive statistics of these variables in our samples. Recall that both samples are restricted to specific cohorts of middle-aged males, that were between 24 and 59 when the Census was taken in 2004 and between 30 and 65 at the time of the LFS, in 2010. The table shows that our sample of males have on average more than 7 years of education, one more than the length of primary school. Employment rates are unsurprisingly high, at around $80 \%$. The wealth index has no natural interpretation of units but it is useful to notice the scale of the index as proxied by a standard deviation of 2 (the index ranges roughly from -10 to 10 ).

Table 1 Descriptive statistics

\begin{tabular}{|c|c|c|c|c|}
\hline & Mean cns & SD cns & Mean Ifs & SD Ifs \\
\hline Grades completed & 7.562 & 5 & 7.867 & 5 \\
\hline Wealth index & 0.150 & 2 & 0.773 & 2 \\
\hline Employed & 0.787 & & 0.830 & \\
\hline \multicolumn{5}{|l|}{ Education } \\
\hline None & 0.141 & & 0.116 & \\
\hline Primary & 0.381 & & 0.405 & \\
\hline Secondary & 0.345 & & 0.341 & \\
\hline College & 0.134 & & 0.139 & \\
\hline \multicolumn{5}{|l|}{ Employment sector } \\
\hline Public admin & 0.190 & & 0.172 & \\
\hline Public company & 0.032 & & 0.034 & \\
\hline Private Tunisian company & 0.139 & & 0.124 & \\
\hline Multinat & 0.023 & & 0.031 & \\
\hline Shop & 0.144 & & 0.168 & \\
\hline Home & 0.007 & & 0.005 & \\
\hline Ambulant & 0.070 & & 0.062 & \\
\hline Agricultural site & 0.106 & & 0.123 & \\
\hline Construction building & 0.126 & & 0.139 & \\
\hline Construction other & 0.006 & & 0.006 & \\
\hline Other places & 0.013 & & 0.011 & \\
\hline None & 0.143 & & 0.124 & \\
\hline \multicolumn{5}{|l|}{ Occupation } \\
\hline Management & 0.088 & & 0.133 & \\
\hline Scientist & 0.053 & & 0.057 & \\
\hline Technician & 0.061 & & 0.054 & \\
\hline Clerk & 0.045 & & 0.038 & \\
\hline Vendor & 0.096 & & 0.089 & \\
\hline Farmer & 0.074 & & 0.101 & \\
\hline Craftsman & 0.128 & & 0.121 & \\
\hline Machine Operator & 0.087 & & 0.083 & \\
\hline Unskilled Worker & 0.225 & & 0.168 & \\
\hline None & 0.143 & & 0.156 & \\
\hline
\end{tabular}

Males born between 1945 and 1980. Cns refers to the census data and Ifs to the labor force survey. Employment sector refers to the response to a question about place of work. 
Table 1 shows that the public sector is a significant, although not massive, provider of employment. Around one fourth of the employed in our samples work in the public sector, either in the administration (most of them), or in public companies. Employment in private companies is somewhat lower but not substantially so, as are employment in agricultural fields and at construction sites. From here onwards our interest will lie in the first four employment sectors (public administration, public companies, private Tunisian companies and multinationals), and we will lump together the other workplaces. Regarding occupations, in what follows we will be focusing specifically on white collar occupations (managers, scientists, technicians, and clerks), and we will disaggregate these further when useful.

The last feature to notice in Table 1 is the similarity between the census and the LFS figures, which gives certain confidence on the quality of the data. The main differences between the two samples are the slightly higher proportion of employed and managers in the LFS, both of which are consistent with the cohorts being older in that sample.

As a first pass at the question of skill absorption by the public sector, Table 2 displays the skill distribution within the different sectors. The numbers in Table 2 do suggest that the public sector is skill intensive. In particular, the public administration employs the largest share of workers with college, relative to other sectors. Still, both public and private sector companies are skill intensive relative to the other workplaces. Private Tunisian companies are slightly less skilled intensive than the other types of companies. The differences in skill are broadly mirrored in differences in average wealth of workers in different sectors. Notice also that public companies and multinationals are very similar in skill composition (as well as in size, as could be seen in the previous table). In the analysis below it will often be useful to focus on comparisons between these two sectors.

That the public administration is the most skill intensive need not imply that the public sector is absorbing college students inefficiently. The technological requirements of public administration may be such that comparatively more skills are needed to perform its tasks. We thus examine whether the differences in skill appear to be driven by differences in occupation types or to skill levels within occupations. Table 3 shows the distribution of occupations across sectors, where we have disaggregated white collar occupations into subcategories. The last row shows the marginal distribution of sectors, for comparison. It is clear that there are strong differences in occupation across sectors. Our four selected sectors have a clear overrepresentation of top occupation categories relative to the "other" workplaces. The same applies to the public administration, relative to public and private companies. The public administration employs a disproportionate share of education and health workers, occupations with high skill requirements.

Table 2 Distribution of skill and mean wealth by sector

\begin{tabular}{lcccccc}
\hline & None & Primary & Secondary & College & Grades completed & Wealth \\
\hline Public admin & 0.050 & 0.17 & 0.46 & 0.329 & 11.3 & 1.22 \\
Public company & 0.066 & 0.28 & 0.48 & 0.166 & 9.2 & 1.28 \\
Private Tunisian company & 0.066 & 0.35 & 0.44 & 0.149 & 8.7 & 0.75 \\
Multinat & 0.036 & 0.30 & 0.48 & 0.186 & 9.5 & 1.04 \\
Others & 0.194 & 0.51 & 0.27 & 0.028 & 5.5 & -0.55 \\
None & 0.194 & 0.31 & 0.30 & 0.191 & 7.7 & -0.29 \\
\hline
\end{tabular}


Table 3 Distribution of sectors by occupation

\begin{tabular}{|c|c|c|c|c|c|c|}
\hline & $\begin{array}{l}\text { Public } \\
\text { admin }\end{array}$ & $\begin{array}{l}\text { Public } \\
\text { company }\end{array}$ & $\begin{array}{l}\text { Private } \\
\text { Tunisian } \\
\text { company }\end{array}$ & Multinat & Others & None \\
\hline \multicolumn{7}{|l|}{ Management } \\
\hline Senior Govt and CEO & 0.943 & 0.0223 & 0.015 & 0.0045 & 0.014 & 0.001 \\
\hline Company Director & 0.324 & 0.0952 & 0.443 & 0.0918 & 0.043 & 0.003 \\
\hline SME Manager & 0.007 & 0.0049 & 0.100 & 0.0057 & 0.881 & 0.002 \\
\hline \multicolumn{7}{|l|}{ Scientist } \\
\hline Natural Scientist & 0.323 & 0.1363 & 0.361 & 0.0875 & 0.089 & 0.003 \\
\hline Life Scientist & 0.522 & 0.0276 & 0.088 & 0.0146 & 0.345 & 0.002 \\
\hline $\begin{array}{l}\text { Secondary and University } \\
\text { Teacher }\end{array}$ & 0.965 & 0.0076 & 0.010 & 0.0018 & 0.014 & 0.001 \\
\hline Other Scientist & 0.361 & 0.0568 & 0.291 & 0.0481 & 0.240 & 0.004 \\
\hline \multicolumn{7}{|l|}{ Technician } \\
\hline Natural Science Technician & 0.277 & 0.1544 & 0.350 & 0.0875 & 0.130 & 0.002 \\
\hline Life Science Technician & 0.778 & 0.0377 & 0.086 & 0.0103 & 0.087 & 0.001 \\
\hline Primary School Teacher & 0.920 & 0.0079 & 0.018 & 0.0007 & 0.051 & 0.002 \\
\hline Other Technician & 0.378 & 0.0649 & 0.336 & 0.0545 & 0.162 & 0.005 \\
\hline \multicolumn{7}{|l|}{ Clerk } \\
\hline Secretary & 0.585 & 0.0961 & 0.228 & 0.0393 & 0.048 & 0.003 \\
\hline Receptionist & 0.373 & 0.1319 & 0.308 & 0.0535 & 0.131 & 0.003 \\
\hline \multicolumn{7}{|l|}{ Others } \\
\hline Vendor & 0.376 & 0.0180 & 0.131 & 0.0211 & 0.451 & 0.003 \\
\hline Farmer & 0.016 & 0.0057 & 0.019 & 0.0028 & 0.956 & 0.001 \\
\hline Craftsman & 0.043 & 0.0353 & 0.175 & 0.0236 & 0.721 & 0.002 \\
\hline Machine Operator & 0.117 & 0.0680 & 0.312 & 0.0525 & 0.448 & 0.004 \\
\hline Unskilled Worker & 0.116 & 0.0284 & 0.134 & 0.0249 & 0.694 & 0.002 \\
\hline None & 0.006 & 0.0004 & 0.003 & 0.0005 & 0.003 & 0.987 \\
\hline \multicolumn{7}{|l|}{ All } \\
\hline All & 0.190 & 0.0322 & 0.139 & 0.0234 & 0.472 & 0.144 \\
\hline
\end{tabular}

In order to check if, in addition to differences in occupational structure, the public administration displays high skill intensity also within occupations, we select certain occupational categories. We do so because making cross sectoral comparisons within occupations that are not homogeneously distributed across sectors are likely to be misleading (for instance, the tiny amount of education workers in the multinational sector are likely to be essentially different than the large amount of public sector educational workers; comparisons between them are likely to be potentially misleading). We will thus focus on occupations that are roughly proportionately distributed across sectors: among management we select company directors; as scientists and technicians we select scientific and other occupations; and as clerical jobs we select both subcategories.

Table 4 shows the average grades completed within the selected occupation categories and sectors. Within each occupation category, mean education levels are relatively similar across sectors (except "other scientists", that display lower education levels in the public administration). Certainly there are no large systematic differences between sectors: the unusual skill intensity of the public administration appears to be due to its occupation composition rather than the skill content in each occupation.

Table 4 also provides some additional confidence regarding the quality of the data used. Education levels by occupation category are sensible, with highest levels for scientists and 
Table 4 Mean grades completed and wealth by occupation and sector

\begin{tabular}{lccccccc}
\hline & \multicolumn{3}{c}{ Grades completed } & & Wealth \\
\cline { 2 - 5 } & $\begin{array}{l}\text { Public } \\
\text { admin }\end{array}$ & $\begin{array}{c}\text { Public } \\
\text { company }\end{array}$ & $\begin{array}{c}\text { Private } \\
\text { Tunisian } \\
\text { company }\end{array}$ & Multinat & All & All \\
\hline Company Director & 15.0 & 14.6 & 14.0 & 14.1 & 14.3 & 3.47 \\
Natural Scientist & 16.6 & 16.9 & 16.9 & 17.2 & 16.8 & 3.36 \\
Other Scientist & 13.5 & 14.9 & 15.5 & 15.7 & 14.8 & 2.43 \\
Natural Science Technician & 12.5 & 12.2 & 12.1 & 12.8 & 12.0 & 1.63 \\
Other Technician & 11.9 & 11.3 & 11.8 & 12.0 & 11.3 & 1.62 \\
Secretary & 10.8 & 10.3 & 10.9 & 11.0 & 10.8 & 1.26 \\
Receptionist & 9.8 & 10.4 & 10.6 & 11.3 & 10.0 & 1.25 \\
\hline
\end{tabular}

lowest levels for clerks. The table shows in its last column the mean wealth level for each occupation category. Here again, results are reassuring, with wealth levels increasing with the occupational hierarchy. Consistent with what one would expect directors display on average slightly higher wealth levels than natural scientists, despite their lower average educational attainment.

In summary, the descriptive analysis does not point to any obvious overhiring of educated workers by the public sector. Public companies have similar skill distributions than private ones (particularly multinational ones). The public administration does employ more college graduates than public and private companies, but this appears to be mainly related to the specific occupational structure of the public sector and not the skill content within occupations. However, it is important to note that the descriptive statistics presented here do not really inform us about the effect of educational attainment on the employment status. Since education is likely to be correlated with other determinants of employment status the correlations between education and allocation of workers in these table is, at least partly, spurious. To understand how educational attainment affects employment status among Tunisian men, we exploit the policy changes of the 1970's in the following section.

\section{Results}

The hypothesis we attempt to test with our instrumental variable identification strategy is that the Tunisian public sector absorbs workers with skills, obtained through education, that are unrewarded in the open sector. Hence, we would expect educational attainment to affect the probability of working in specific occupations in the public sector positively, while there should be no effect on working in these occupations in the multinational sector.

We test this hypothesis by regressing the probability of being employed in selected occupations in the public, private Tunisian, and multinational sectors on educational attainment. We denote these probabilities with $Y_{i, s, o}$, where $i$ refers to individuals, $s$ to sectors and $o$ to occupations. The empirical framework for estimating these effects is given by:

$$
Y_{i, s, o}=f\left(C_{i}\right)+\beta \mathrm{SCH}_{i}+\epsilon_{i, s, o}
$$

where $C_{i}$ denotes the birth cohort of individual $i$ and $\mathrm{SCH}_{i}$ refers to $i$ 's level of schooling measured by grades completed. We specify the function $f$ as a flexible polynomial of birth 
year and in our baseline regressions we use a polynomial of order three. We also apply polynomials of order five in robustness checks ${ }^{5}$.

However, since educational attainment is likely to be correlated with unobservable determinants of employment outcomes, the level of schooling $\mathrm{SCH}_{i}$ will be correlated with the error term $\epsilon$ in (1). Typical examples of sources of such omitted variable bias are unobserved ability and the financial resources of the family, both of which are likely to be positively correlated with educational attainment as well as employment. To overcome this endogeneity problem we exploit the policy reform described in section 2 , and specify $\mathrm{SCH}_{i}$ as:

$$
\mathrm{SCH}_{i}=f\left(C_{i}\right)+\gamma R_{i}+v_{i}
$$

where $R_{i}$ is our reform variable. We first report estimates for sectors aggregating across all occupations and in a second step we show the results disaggregated by occupation.

The reform variable $R$ is coded as follows. As was explained above the regime decreased access to secondary education in 1971 and then increased it again in 1980. As the secondary school entry age in the Tunisian system is 12 , without any grade repetition this variable would take values one for cohorts born between 1959 and 1968 and zero otherwise. However, due to widespread grade repetition some cohorts born before 1959 were also affected by the stricter access requirements of 1971. In the same way, parts of the cohorts born between 1964-1968 were affected by the more lenient regime. In order to take into account repetition rates in this manner, we use information detailing the year-of-birth composition of each primary school grade in (Ministère de l'Education Nationale 1983) and extrapolate this information to the two instances of policy change. We end up with exposure equaling one for the cohort reaching 12 in 1971 (born in 1969), and decreasing almost linearly for 4 older cohorts ( 0.8 for those born in 1958, 0.53 for those born in 1957, etc.). The reverse applies to the 1980 policy change.

For our reform variable $R_{i}$ to be a valid instrument for schooling it needs to be correlated with schooling and not to be correlated with any determinants of employment status that are excluded from equation (1). Figure 2 depicts the values of the variable $R$ by birth cohorts. We believe that the specific form of our instrument, implying not only one policy change, but two changes (the drop in promotions rates and the subsequent recovery) at arbitrary points in time, lends credibility to the validity of the instrument. It is possible that the education policy changes in 1971 and 1980 were accompanied by public sector employment reforms. Even in that case, however, this would be unlikely to threat the validity of our instrument. The reason is that the instrument refers to cohorts turning 12 years old between 1971 and 1980. These cohorts would have been too young at those times to be affected by any possible contemporaneous public sector reform.

\subsection{First stage results}

The OLS estimates of the effect of the policy reform on grades completed is reported in Table 5. As is clear from the table, the reform decreased the amount of grades completed by approximately one, a relatively large amount. The satisfactory performance of the instrument is also apparent when inspecting graphs of educational attainment by cohort. Figure 3 shows grades completed by birth cohort, using the census data. Together with the 


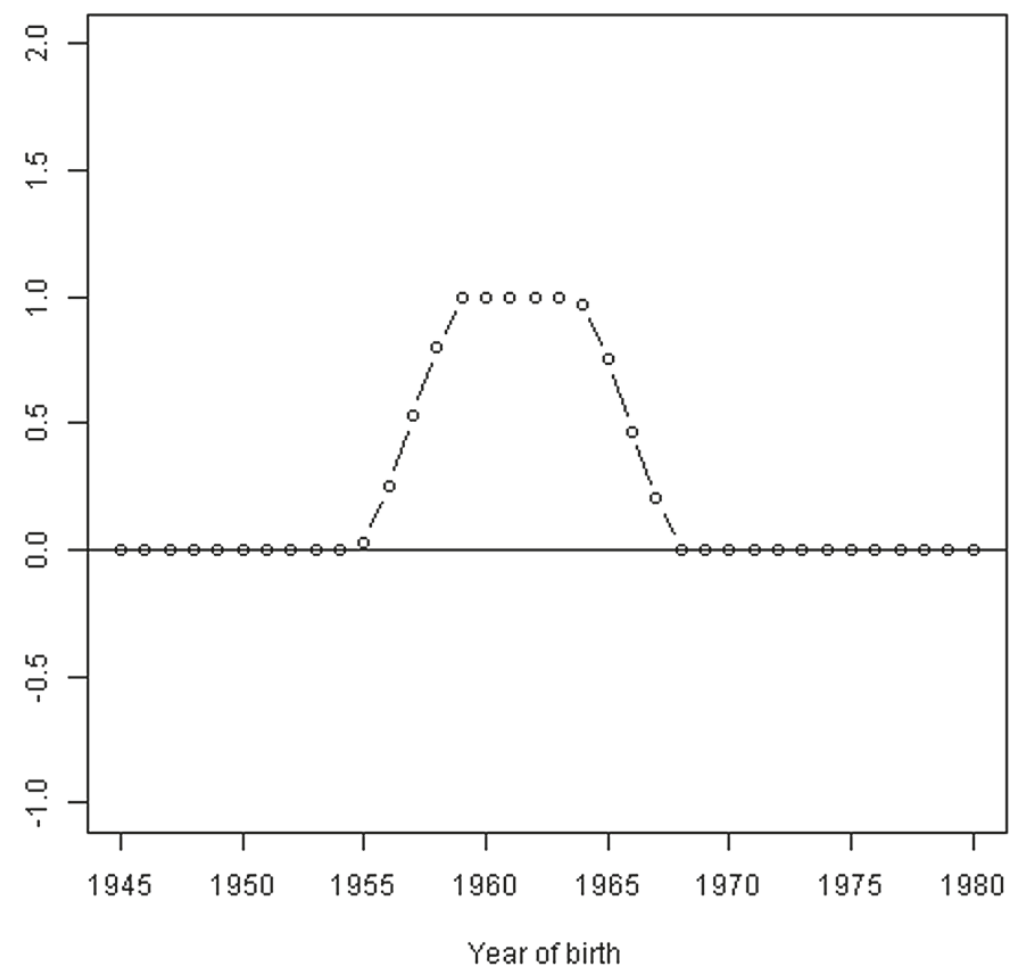

Figure 2 Value of the instrument by birth cohort.

means by cohort, the figure shows predictions from the first-stage regressions (3rd order polynomial) with the instrument turned on (solid line) and also turned off (dashed line). Together Table 5 and Figure 3 clearly show that restricting access to secondary education in the 1970's had an effect on educational attainment.

In order to assess the trustworthiness of our instrument, we compare the distribution of grades completed by nearby cohorts distinguishing between those fully exposed to the policy and those not exposed. Figure 4 shows the CDFs of cohorts born in 1959 or 1964 (first and last fully exposed to the low promotion regime) and those born in 1954 and 1968 (closest cohorts among the not exposed). The vertical lines in the figure correspond to the grades at which primary, secondary and the standard tertiary education end. The distribution of grades completed of exposed cohorts is first-order dominated by that of cohorts not exposed. Most importantly, the two cohorts have the same distribution up to the end of primary school, where they diverge substantially. This is in line with the

Table 5 First stage regressions of grades completed on exposure to the reform

\begin{tabular}{llll}
\hline & $\mathbf{1}$ & $\mathbf{2}$ & $\mathbf{3}$ \\
\hline Grades completed & -0.952 & -0.785 & -0.992 \\
& $(0.034)^{* * *}$ & $(0.058)^{* * *}$ & $(0.073)^{* * *}$ \\
\hline Data.used & cns & cns & Ifs \\
Poly.order & 3 & 5 & 3 \\
$\mathrm{~N}$ & 352129 & 352129 & 77982
\end{tabular}

Robust standard errors in parenthesis. Signif. codes: $0.01^{1 * * * \prime} 0.05^{\prime * * \prime} 0.1^{\prime * \prime}$. OLS regressions of grades completed on the reform exposure instrument using different specifications and datasets. Cns refers to the census data and Ifs to the labor force survey. 


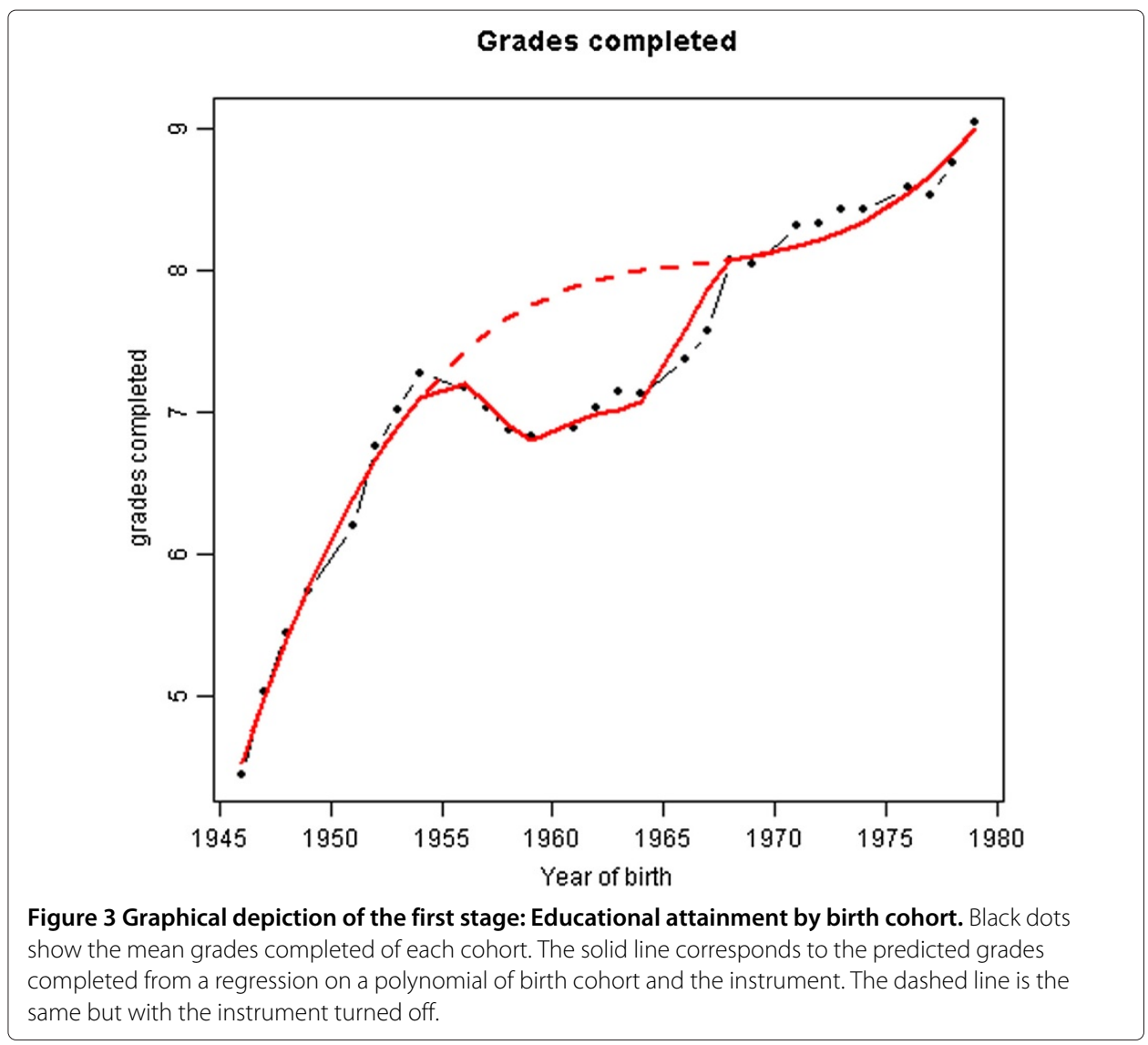

postulated effect of the reform we use as instrument, which restricted access to secondary school.

Figure 4 also shows that the reform had a complex effect on educational attainment. The reform had the largest impact at the secondary school level, but also led to some clear differences at the university level. In other words, it seems that the reform blocked the entrance to secondary school for some students that would have dropped out of school during secondary school as well as for some students who would have continued all the way to university. This complexity is also apparent when considering the differences between the exposed and unexposed cohorts in terms of diplomas obtained, as shown in Table 6. This table clearly reveals that restricting access to secondary school led to significant declines in the shares of individuals with only secondary degrees or bachelors degrees from university. Hence, the policy reform was effective in blocking individuals from completing secondary or tertiary education. At the same time, it didn't lead to substantial decreases in the share of individuals with vocational degrees or $\mathrm{PhD}^{6}{ }^{6}$.

The policy we use as instrument thus clearly led to a decrease in educational attainment for the affected cohorts. However, attainment was affected in such a complex way that we are not able to use our instrument to disentangle the effect of secondary education from that of university education or the effect of titles from that of the learning coming from additional years of education. Our choice of endogenous variable is thus to a certain extent arbitrary, and we choose grades completed for clarity. 


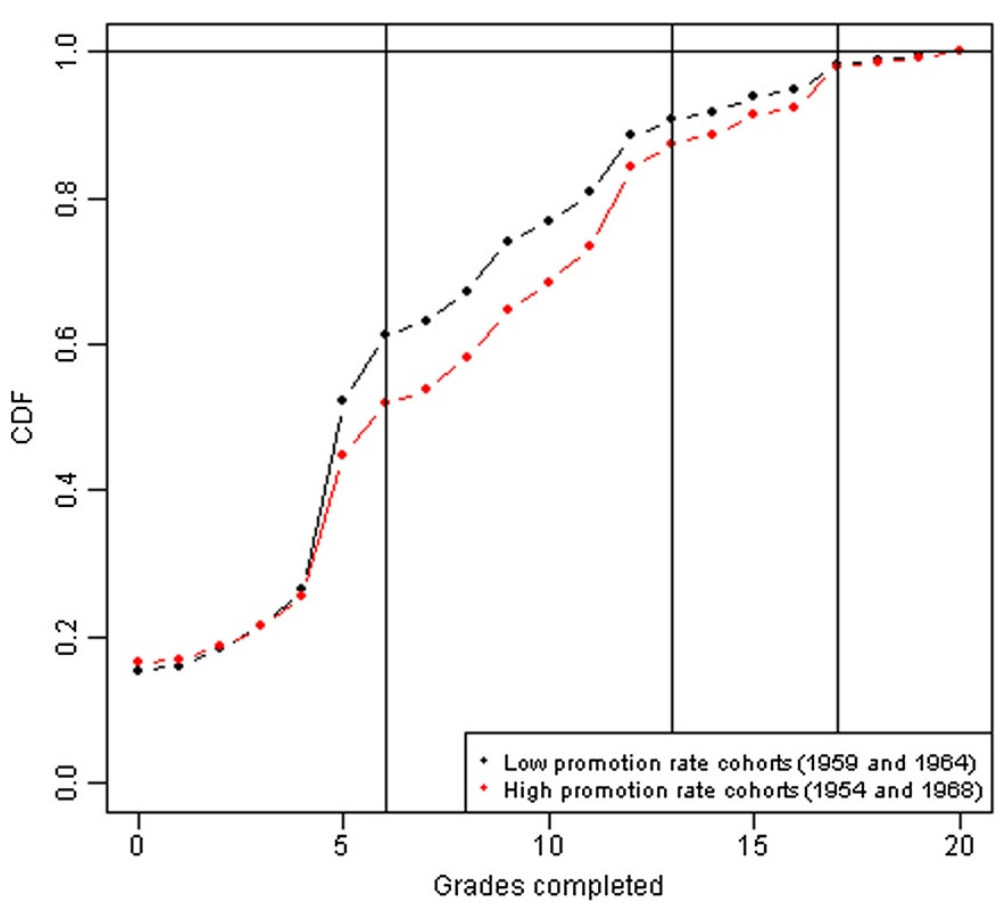

Figure 4 Distribution of grades completed of nearby exposed and unexposed birth cohorts. Low promotion cohorts are those born in 1959 and 1964, the first and last to be fully exposed to the reduction in promotion rates into secondary school. High promotion cohorts are those born in 1954 and 1968, the cohorts closest to the above fully unexposed to the reduction in promotion rates.

\subsection{The effect of education on occupational status}

The first question we consider is the effect of education on the probability of obtaining employment in the public sector and in private companies. Table 7 reports both IV and OLS results, using our two datasets. Consider first the IV results using the census data. All coefficients are positive and statistically significant at conventional levels. The chances of working in the public sector and in private companies increase with the number of grades completed. The coefficients differ substantially across sectors, partly because the sectors are of substantially different size. However, differences remain large even when focusing on the size of the coefficient relative to the size of the sector (as given in the before-last row). For the public administration, where around $20 \%$ of the workforce are employed, the mere fact of obtaining a one more grade of schooling increases the chances

Table 6 Diplomas obtained by nearby exposed and unexposed cohorts

\begin{tabular}{lcccc}
\hline & High promotion & Low promotion & Difference & P-value difference \\
\hline Vocational training & 0.050 & 0.055 & -0.005 & 0.021 \\
Diploma before & 0.039 & 0.035 & 0.004 & 0.017 \\
completed secondary & & & & \\
Secondary school only & 0.039 & 0.029 & 0.010 & 0.000 \\
University BA/MA & 0.074 & 0.053 & 0.021 & 0.000 \\
PhD & 0.004 & 0.004 & 0.001 & 0.178 \\
Other diplomas & 0.028 & 0.032 & -0.004 & 0.008 \\
\hline
\end{tabular}

Low promotion cohorts are those born in 1959 and 1964, the first and last to be fully exposed to the reduction in promotion rates into secondary school. High promotion cohorts are those born in 1954 and 1968, the cohorts closest to the above fully unexposed to the reduction in promotion rates. 
Table 7 IV and OLS estimates of the effect of education on sector of employment

\begin{tabular}{lllll}
\hline & $\mathbf{1}$ & $\mathbf{2}$ & $\mathbf{3}$ & $\mathbf{4}$ \\
\hline IV.cns & 0.0556 & 0.0070 & 0.0116 & 0.00378 \\
& $(0.0028)^{* * *}$ & $(0.0014)^{* * *}$ & $(0.0024)^{* * *}$ & $(0.00098)^{* * *}$ \\
OLS.cns & 0.02871 & 0.002457 & 0.00543 & 0.001593 \\
IV.Ifs & $(0.00015)^{* * *}$ & $(0.000066)^{* * *}$ & $(0.00012)^{* * *}$ & $(0.000056)^{* * *}$ \\
& 0.057 & 0.0051 & 0.0012 & 0.0022 \\
OLS.Ifs & $(0.011)^{* * *}$ & $(0.0059)$ & $(0.0095)$ & $(0.0046)$ \\
& 0.02822 & 0.00394 & 0.00545 & 0.00238 \\
Outcome.var & $(0.00033)^{* * *}$ & $(0.00017)^{* * *}$ & $(0.00028)^{* * *}$ & $(0.00016)^{* * *}$ \\
& Public admin & Public company & Private Tunisian & Multinat \\
Mean.outc & 0.18 & & company & \\
SD.outc & 0.39 & 0.04 & 0.13 & 0.03 \\
\hline
\end{tabular}

Robust standard errors in parenthesis. Signif. codes: $0.01^{\prime * * * \prime} 0.05^{\prime * * \prime} 0.1^{\prime * \prime}$. Coefficients for grades completed in OLS and 2 SLS regressions of working in different sectors on grades completed and a birth cohort polynomial. Outcome variables are dummy variables taking value one if the individual works in the respective sector and zero otherwise. 2SLS estimates use reform exposure as instrument. Cns refers to the census data and Ifs to the labor force survey. Mean.outc and SD.outc refer to the mean and the standard deviation of the respective outcome.

of working there by a staggering $33 \%$. The effect is also very large for public companies at $18 \%$. The effects are smallest in relative terms (though still significant) for the private sector companies, where an additional grade leads to $10 \%$ increase in the probability of working in the sector. The estimates are somewhat reduced when using the LFS instead of the census.

An important thing to note in Table 7 is that the OLS estimates tend to be lower than the IV ones. At first sight, this pattern of result would seem difficult to reconcile with the interpretation that the compliers of our instrument are the academically weak students. Indeed, the traditional LATE interpretation of the IV estimates would in that case imply that IV estimates should be lower than the OLS estimates ${ }^{7}$. Often downward biases in OLS estimates are explained by measurement error in education variables. However, in our case the most likely interpretation for this pattern of results is that the substantial non-linearities in the impact of education on the sector of employment are causing the IV estimates to exceed OLS estimates.

Figure 5 sheds light on the non-linearity in the association between education and the sector of employment. The figure reports the OLS estimates of the impact of education on the probability of working in the public sector and multinational companies using dummies for grades completed as education variables. As is obvious from Figure 5, the OLS association between schooling and the probability of working in the public sector is strongest between grades 6 to 13 which correspond to grades in secondary school. Our instruments affect education precisely in these ranges (see Figure 4 above). If we reestimate the OLS regressions of Table 7 using the sub-sample of grades 5 to 12, where the reform had its biggest effect, we obtain OLS estimates that are closer to the IV estimates in Table 7. For example, the OLS estimate of the effect of schooling on the probability or working in the public sector is 0.039 whereas the IV estimate using the whole sample was 0.056 in Table 7. Hence, a modified LATE explanation for the high IV estimates is that our instrument is affecting education at grades where the effect on the public sector is particularly high. This pattern of results is very similar to what Riddell and Song (2001) report when estimating the effect of schooling on the incidence of unemployment in the U.S. 

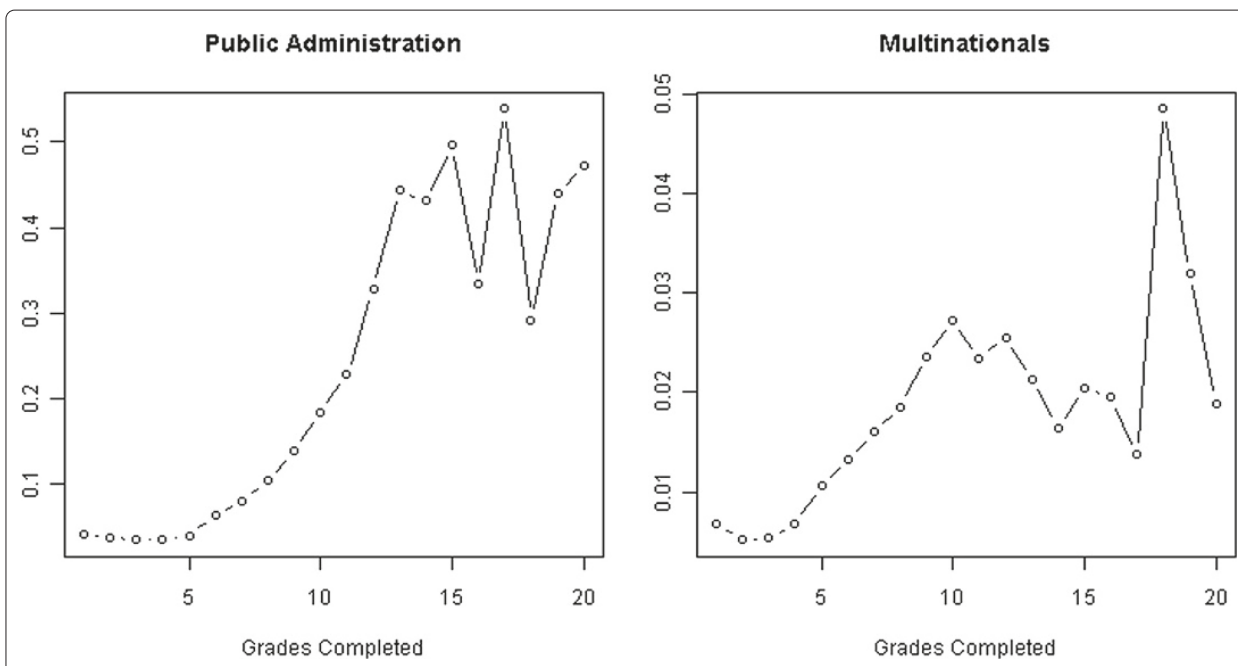

Figure 5 Probablility of working in the public sector administration and multinational companies by grades completed. Coefficients of a regression of working in the public administration (left panel) and in multinationals (right panel) on a full set of grades completed dummies.

Furthermore, the non-linearity of the OLS estimates is consistent with "sheepskin effects" associated with the completion of secondary school, an issue we return to below ${ }^{8}$.

Table 8 shows the IV estimates of educational attainment on the probability of working in the selected occupations by sector. In addition to coefficients and standard errors, the table reports the size of each occupation in each sector. The coefficients of the table are generally positive with two important types of exception. First, coefficients on natural science scientific/technical occupations are essentially zero, for all sectors. Second, coefficients are generally essentially zero for the multinational sector, except for clerical jobs. The coefficients for company directors and "other scientists" (economists, lawyers, etc.) is thus positive for the public sector, but zero for the multinational sector. To illustrate this pattern of results, we present the reduced from effects of the reform on working as a company director in different industries in Figure 6. The graphs in this figure plot the fraction of the labor force employed in this occupation by sector as well as the predictions from regressions where the probabilities are regressed on the 3rd order polynomial of birth cohorts with the instrument turned on (solid line) and off (dashed line) ${ }^{9}$. These figures show the dramatic drop in the probability of working as a director in the public sector while there is essentially no drop in the case of multinationals.

\subsection{Discussion of the results}

The results presented above indicate that the changes in educational attainment generated by the policy changes in the 1970's clearly had an effect on the employment status of Tunisian men. The pattern of effects we find suggests that the public sector rewards skills or features of the formal education that appear to have little value for the more open sector. Education has a strong effect on the probability of working in most white collar occupations in the public sector, whereas it has essentially no effect on most occupations in the multinational sector.

As is always the case with instrumental variables, these results do not tell us anything about whose education and labor market status was effected. In our case, the nature of 
Table $8 \mathrm{IV}$ results on the effect of education on different occupations and sectors

\begin{tabular}{llllll}
\hline & Public admin & Public company & $\begin{array}{l}\text { Private Tunisian } \\
\text { company }\end{array}$ & Multinat & All \\
\hline Company Director & 0.00491 & 0.00137 & 0.00313 & 0.00053 & 0.0103 \\
& $(0.00067)^{* * *}$ & $(0.00039)^{* * *}$ & $(0.00076)^{* * *}$ & $(0.00033)$ & $(0.0011)^{* * *}$ \\
& {$[0.006]$} & {$[0.002]$} & {$[0.009]$} & {$[0.002]$} & {$[0.020]$} \\
Natural Scientist & -0.00048 & 0.00019 & -0.00014 & -0.000059 & -0.000078 \\
& $(0.00047)$ & $(0.00029)$ & $(0.00044)$ & $(0.000221)$ & $(0.000779)$ \\
& {$[0.003]$} & {$[0.001]$} & {$[0.004]$} & {$[0.0009]$} & {$[0.010]$} \\
Other Scientist & 0.00228 & 0.00011 & 0.00122 & 0.00022 & 0.00498 \\
& $(0.00046)^{* * *}$ & $(0.00019)$ & $(0.00034)^{* * *}$ & $(0.00015)$ & $(0.00071)^{* * *}$ \\
Natural Science & {$[0.004]$} & {$[0.0006]$} & {$[0.003]$} & {$[0.0005]$} & {$[0.010]$} \\
Technician & 0.00027 & 0.00024 & 0.00058 & -0.00024 & 0.00059 \\
& & & & & \\
Other Technician & $(0.00051)$ & $(0.00039)$ & $(0.00046)$ & $(0.00022)$ & $(0.00087)$ \\
& {$[0.004]$} & {$[0.002]$} & {$[0.005]$} & {$[0.001]$} & {$[0.015]$} \\
& 0.00154 & 0.00063 & 0.00179 & -0.000000011 & 0.00397 \\
Secretary & $(0.00061)^{* *}$ & $(0.00026)^{* *}$ & $(0.00053)^{* * *}$ & $(0.00019530)$ & $(0.00093)^{* * *}$ \\
& {$[0.006]$} & {$[0.001]$} & {$[0.005]$} & {$[0.0009]$} & {$[0.016]$} \\
& 0.0078 & 0.00109 & 0.00332 & 0.00048 & 0.0129 \\
Receptionist & $(0.0011)^{* * *}$ & $(0.00049)^{* *}$ & $(0.00069)^{* * *}$ & $(0.00026)^{*}$ & $(0.0014)^{* * *}$ \\
& {$[0.02]$} & {$[0.003]$} & {$[0.008]$} & {$[0.001]$} & {$[0.036]$} \\
& 0.00075 & 0.00091 & 0.00146 & 0.00027 & 0.00397 \\
& $(0.00046)$ & $(0.00028)^{* * *}$ & $(0.00035)^{* * *}$ & $(0.00014)^{* *}$ & $(0.00069)^{* * *}$ \\
& {$[0.003]$} & {$[0.001]$} & {$[0.003]$} & {$[0.0005]$} & {$[0.009]$} \\
\hline
\end{tabular}

Coefficients for grades completed in OLS and 2SLS regressions of working in different occupations and sectors on grades completed and a birth cohort polynomial. Outcome variables are dummy variables taking value one if the individual works in the respective occupation and sector and zero otherwise (i.e. the first cell uses a dummy with value one for individuals working as company directors in the public sector and zero for the rest). 2SLS estimates use reform exposure as instrument. All estimates use the census data. The figures in square brackets show the proportion of the workforce in each occupation in each sector. Robust standard errors in parenthesis. Signif. codes: $0.01^{2 * * * \prime} 0.05^{2 * * \prime} 0.1^{\imath * \prime}$.

the policy change that we use to instrument educational attainment suggests that those whose education was affected by the policy were the ones on the margin of gaining an access to secondary school. Hence, we are most likely estimating the effects of educational attainment on the employment status for individuals that are among the weakest students who continue their studies beyond primary school. The results in Table 8 provide further suggestive evidence that, in our opinion, supports the interpretation that the compliers are academically weaker students. According to these results formal education did not help the the compliers of our instrument to obtain white collar jobs in natural science occupations, where the technical skills acquired at school are most necessary. This interpretation is reinforced by the fact that the reform did not affect the acquisition of $\mathrm{PhD}$ diplomas.

If one accepts this interpretation, our IV results suggest that both the public and, to a lesser extent, the Tunisian corporate sector do absorb certain types of workers by virtue of their formal education, regardless of skill. This pattern is most remarkable when it comes to managers. We find strong effects of education on obtaining managerial positions in the public and private Tunisian sectors, but not in the multinational one. Relative to the size of the occupations in each sector, the size of the effects is very large. For instance, in the public sector, where the effects are largest in relative terms, an additional grade completed increases the chances of becoming a manager by $0.5 \mathrm{pp}$., 

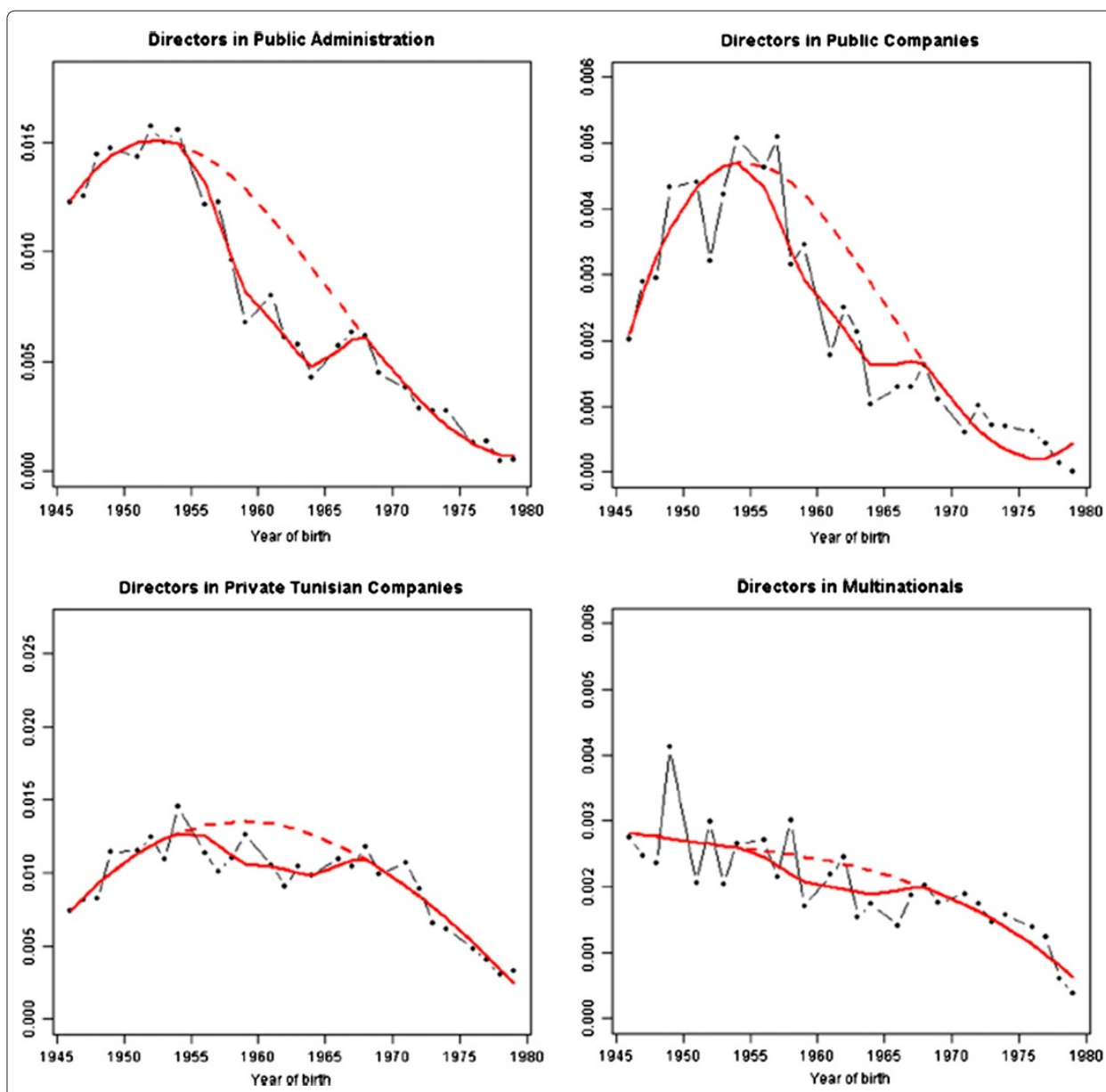

Figure 6 Proportion of company directors by birth year in different sectors. Graphical depiction of the reduced form for company directors in different sectors. Black dots show the share of company directors in the respective sector of each cohort. The solid line corresponds to the prediction of this share from a regression on a polynomial of birth cohort and the instrument. The dashed line is the same but with the instrument turned off.

a large quantity for a type of occupation that employs $0.6 \%$ of the population. Such strong effects of formal education on becoming a manager for a group students likely to be academically weak suggests that it is not primarily skill acquisition, but rather formal titles (i.e. "sheepskin effects") that drives employment and promotions in the public sector.

An alternative explanation for this result could be that multinationals require managers of higher skill than the public sector. Then, the "marginal" students presumably shocked by our instrument would not have become managers in the multinational sector anyway, and the differential results for the public and multinational sectors would emerge without sheepskin effects playing a role ${ }^{10}$. If this alternative explanation was correct, one would expect managers in multinationals to be more skilled than in the public sector. The figures in Table 4, which we discussed above, suggest otherwise. Table 4 clearly shows that managers in the public sector have higher mean years of education than managers in the multinational sector. To probe further into the matter it is useful to check the full education distribution of managers by sector. This is done in Figure 7. The distributions of the 


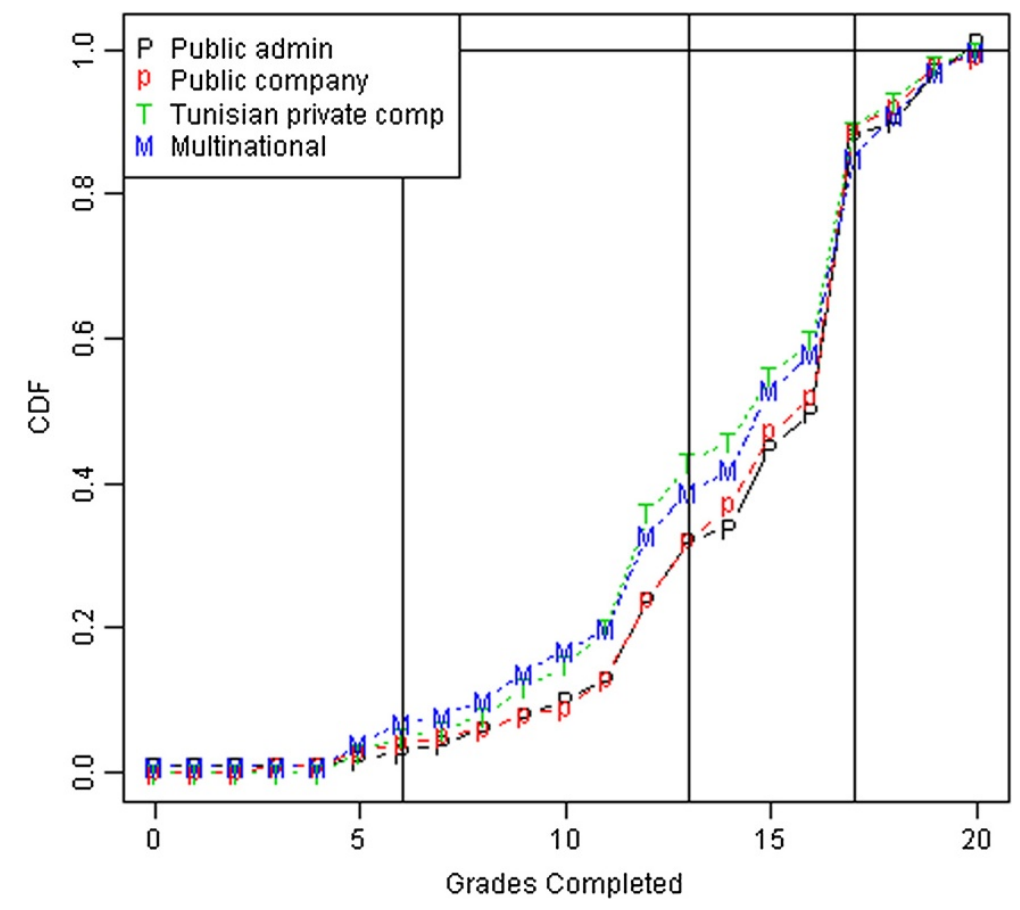

Figure 7 Distribution of grades completed for managers in different sectors.

four sectors look very similar. If anything, public sector managers appear slightly more educated overall, thus making this alternative explanation unlikely.

\section{Conclusion}

In this paper we estimate the effect of education on occupational status of Tunisian men, with the aim of obtaining insights into the possible inefficient absorption of educated workers into the public sector. We exploit a change in education policy that reduced promotion rates into secondary school from 1971 to 1980. The policy change is shown to have had a substantial effect on educational attainment of the cohorts affected. We use exposure to the policy as instrument for educational attainment.

Our findings suggest a limited acquisition of skills from schooling by the compliers of our instrument. The instrument we use is likely to have shocked the educational attainment of the academically weakest students and, indeed, we find an effect of education on white collar occupations where formal education is likely to be less relevant. In spite of this, we find that formal schooling increases substantially the chances of obtaining a managerial position in the public sector, a pattern not found in the multinational sector. This pattern of results is consistent with "sheepskin" effects, where hiring and promotions are based on titles rather than acquired skill in the public sector.

Our results are thus consistent with misallocation of labor towards and within the public sector. The normative implications of this are however not straightforward. In contexts where clientelism is prevalent (as it is likely to have been in the case of Tunisia during the period considered), the only realistic alternative may be an even more inefficient and inequitable allocation of jobs based on patronage. Having a clear set of rules for hiring and promotions in the public sector may reduce the scope of bureaucratic elites to allocate jobs for their personal gain. 


\section{Endnotes}

${ }^{1}$ Our identification strategy is very similar to the one that Harmon and Walker (1995), Oreopoulos (2006), and Pischke and von Wachter (2008) have used to estimate the returns to education in industrialized countries.

${ }^{2}$ The two datasets are available at http://www.ins.nat.tn/modules/nada/index.php/ catalog.

${ }^{3}$ The Labor Force Survey also includes questions on wages. However, this information is not released to researchers.

${ }^{4}$ In our analyses involving wealth, we merge the individual with its corresponding household dataset and we further restrict ourselves to household heads, leading to 294,068 for the Census data and 75,200 for the LFS.

${ }^{5}$ When using the Labor Force Survey data we also include a control variable for retirement in equation (1) since part of our sample has reached the retirement age by 2010.

${ }^{6} \mathrm{The}$ fact that $\mathrm{PhD}$ diplomas are unaffected by the reform reinforces the interpretation that the compliers of the instrument are those relatively academically weak, that would not have proceeded to study a $\mathrm{PhD}$ anyway.

${ }^{7}$ See the discussion in Card (2001) on the traditional LATE interpretation for the pattern the IV estimates of the returns to schooling exceed the OLS estimates.

${ }^{8}$ An additional factor that can help explaining why the OLS estimate is lower than the IV one for the public sector is the presence of age-schooling interaction effects: because young people are more likely to have higher education but less likely to work, the OLS returns to education in terms of employment tend to be lower for the young than for the cohorts affected by the policy. Thus, if in addition to restricting our sample to those with grades 5 to 12, we restrict it also to the cohorts born between 1950 and 1970 (those close to the policy change), the OLS estimate for public sector employment raises further to 0.047 , which is fairly close to the IV estimate.

${ }^{9}$ In order to facilitate comparisons across sectors, the scale of each graph is set relative to the size of the sector.

${ }^{10}$ We would like to thank the editor this insight.

\section{Competing interests}

The IZA Journal of Labor \& Development is committed to the IZA Guiding Principles of Research Integrity. The authors declare that they have observed these principles.

\section{Acknowledgments}

We would like to thank participants of the IZA conference on Labor Markets and Labor Policy in MENA Countries as well as participants of the RP3 GIGA seminar. All errors are ours.

Responsible Editor: David Lam

Author details

${ }^{1}$ Aalto University and IZA, Espoo, Finland. ${ }^{2}$ German Institute of Global and Area Studies (GIGA), Hamburg, Germany.

Received: 10 June 2013 Accepted: 22 November 2013

Published: 30 Dec 2013

\section{References}

Allman J (1979) Social Mobility, Education and Development in Tunisia In: Social, economic, and political studies of the Middle East. Brill, Leiden. isbn 9789004058750, Iccn Ic80473126

Assaad R (1997) The effects of public sector hiring and compensation policies on the Egyptian labor market. World Bank Econ Rev 11(1): 85-118

Bousnina M (1991) Développement scolaire et disparités régionales en tunisie, Vol. 1. Université de Tunis, Tunis

Card D (2001) Estimating the return to schooling: Progress on some persistent econometric problems. Econometrica 69(5): $1127-1160$

Harmon C, Walker I (1995) Estimates of the economic return to schooling for the united kingdom. Am Econ Rev, 85(5): 1278-1286

Makdisi S, Fattah Z, Limam I (2003) Determinants of Growth in the MENA Countries. Arab Planning Institute-Kuwait, Information Center

Ministère de l'Education Nationale (1974) Procès verbaux des reunions tenues. Ministère de l'Education Nationale, Tunis

Ministère de l'Education Nationale (1983) Statistiques de l'enseignement primaire. Ministère de l'Education Nationale, Tunis 
Oreopoulos P (2006) Estimating average and local average treatment effects of education when compulsory schooling laws really matter. Am Econ Rev, 96(1): 152-175

Pischke J-S, von Wachter T (2008) Zero returns to compulsory schooling in germany: Evidence and interpretation. Rev Econ Stat 90(3): 592-598

Pritchett L (2001) Where has all the education gone? World Bank Econ Rev 15(3): 367-391

Riddell WC, Song X (2001) The impact of education on unemployment incidence and re-employment success: Evidence from the us labour market. Labour Econ 18(4): 453-463

Salehi-Isfahani D, Tunali I, Assaad R (2009) A comparative study of returns to education of urban men in egypt, iran, and turkey. Middle East Dev J 1(02): 145-187

Tansel A (2005) Public-private employment choice, wage differentials, and gender in turkey. Econ Dev Cult Change 53(2): 453-477

Tarifa C (1971) L'enseignement du premier et du second degré en tunisie. Population 26(1): 149-180

Tibi C (1974) Développement économique et aspects financiers de la politique d'éducation en tunisie, Vol. 2. Presses de I'Unesco, Paris

10.1186/2193-9020-2-14

Cite this article as: Pekkarinen and Pellicer: Education and allocation of skills in Tunisia: evidence from an education reform. IZA Journal of Labor \& Development 2013, 2:14

\section{Submit your manuscript to a SpringerOpen ${ }^{\circ}$ journal and benefit from:}

$\checkmark$ Convenient online submission

Rigorous peer review

- Immediate publication on acceptance

- Open access: articles freely available online

- High visibility within the field

Retaining the copyright to your article

Submit your next manuscript at $\gg$ springeropen.com 